\title{
Waardenburg syndrome with a fixed dilated pupil
}

\author{
NATHANEL LAOR AND AMOS D. KORCZYN \\ From the Department of Physiology and Pharmacology, Sackler School of Medicine, \\ Tel Aviv University, Ramat Aviv, Israel
}

SUMMARY An unusual case of Waardenburg syndrome associated with a dilated and fixed pupil of the lighter eye is described. Pharmacological investigations were performed to localise the site of the pupillary lesion. A lack of cholinergic reactivity was demonstrated, possibly due to congenital agenesis of the sphincter pupillae. Sympathetic activity was not impaired.

Spiral ganglion agenesis and midline congenital anomalies are common features in Waardenburg syndrome. These lesions as well as the fixed dilated pupil might be due to an embryonal inductive failure.

P. J. Waardenburg delineated a syndrome (Waardenburg, 1951), now bearing his name, consisting of malformation of the inner angle of the eyes, heterochromia iridis, congenital perceptive deafness, and a white forelock. Pupillary anomalies were also described both by Waardenburg (1951) in his original article and by Viswanathan (1973). The present paper describes a pupillary anomaly associated with Waardenburg syndrome (WS) not mentioned previously, namely, a unilateral fixed and dilated pupil.

\section{Case report}

A 71-year-old healthy male immigrant from Romania displayed aniscoria, the right pupil being semidilated and not responding to light or accommodation. In addition he had the following features characteristic of WS: Lateral displacement of the medial canthi and lacrimal puncta. The inner distance measured $47 \mathrm{~mm}$ (normal 26 to $39 \mathrm{~mm}$ ) (DiGeorge et al., 1960). The outer canthal and interpupillary distances were within the normal range ( 96 and $70 \mathrm{~mm}$, respectively). This gave his eyes the appearance of blepharophimosis with partial covering of the medial sclerae (Fig. 1). The lacrimal puncta were also laterally displaced and opened vertically away from the sclera.

Pigmentary changes. (1) Complete heterochromia iridis, the left brown and the right blue (Fig. 1). (2) Heterochromia fundi: pigmentary changes in the

Address for reprints: Dr Amos D. Korczyn, Department of Physiology and Pharmacology, Sackler School of Medicine, Tel Aviv University, Ramat Aviv, Israel fundi corresponding to those of the iris, with the left fundus darker than the right. Goldberg (1966) described such changes in WS. (3) White forelock: the subject was bald when examined, but a sagittal white skin area was observed on the scalp, supporting his story of a white forelock.

Deafness. Congenital right ear deafness, confirmed by audiometry (Fig. 2). A slight hearing loss was found in the left ear as well, which could be explained by the patient's advanced age. No airbone gap was present.

Broad prominence of the nose, with an oblique furrow beginning at a dimple near the tip of the nose (Fig. 3).

Family history consistent with autosomal dominant transmission of the syndrome, with variable expressivity (Fig. 4).

The ophthalmological examination is summarised in Table 1. Apart from the pupillary changes neurological examination revealed no abnormalities. Metopic sutures or a giant jaw (Fisch, 1959) were not found on $x$-ray examinations.

An association of heterochromia and aniscoria is a common feature in Horner syndrome (Waardenburg et al., 1961), but the lighter iris there belongs to the smaller pupil. The fixed dilated pupil of the present case suggested a parasympathetic lesion in the achromatic iris. Studies were carried out to determine pharmacologically the site of the autonomic abnormality.

\section{Material and methods}

The ocular autonomic activity was evaluated by measuring the pupillary diameters in response to 


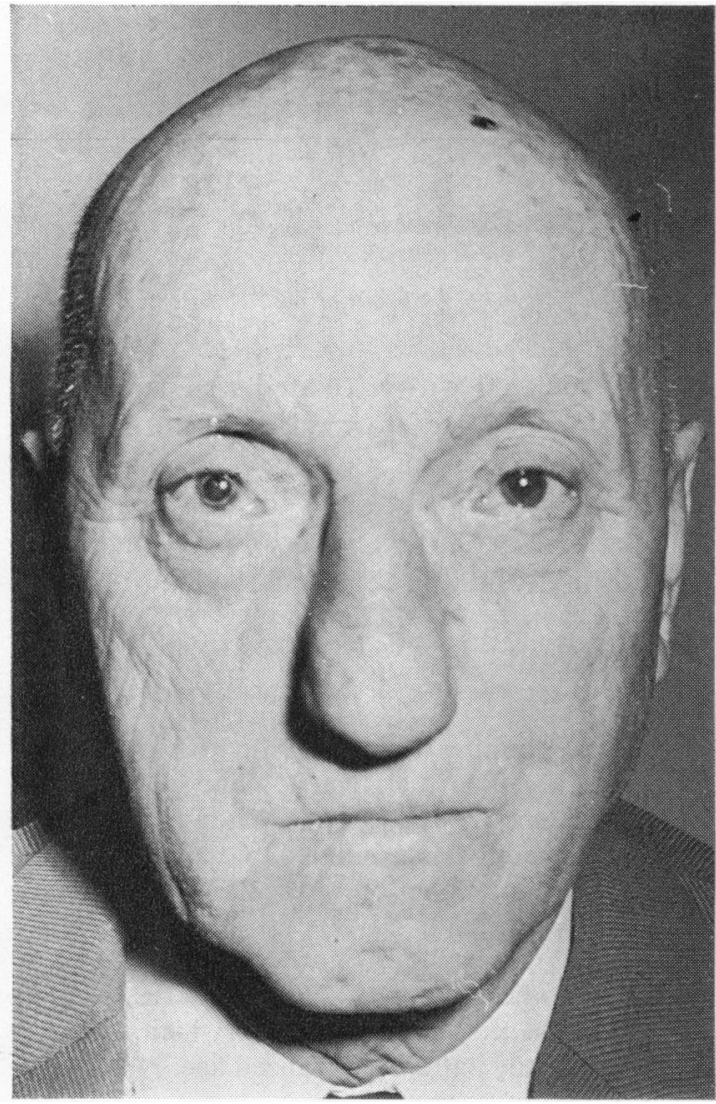

different drugs, given as eye drops. The drugs used were: cocaine $(4 \%)$, hydroxyamphetamine $\mathrm{HCl}$ ( $1 \%)$, phenylephrine $\mathrm{HCl}(5 \%)$, guanethidine $(1 \%)$, pilocarpine $\mathrm{HCl}(0.01$ to $2 \%)$, and phospholine iodide $(0.06$ to $0.12 \%)$. All drugs were given in a dose of $50 \mathrm{mcl}$ into the conjunctival sac of both eyes, except for guanethidine, which was administered in a $250 \mathrm{mcl}$ dose over $10 \mathrm{~min}$. Pupillary responses to sympathomimetic drugs and pilocarpine were measured for 1 hour following application; responses to guanethidine were read after 12 hours and to phospholine iodide after 24 hours. The maximal response was recorded for each (Gambill et al., 1967; Korczyn et al., 1976, Laor et al., 1977). The drugs were given 1 week apart, with a background illumination of $200 \mathrm{Lx}$. Pupillary diameter was measured against a commercial set of black circles while the subject focused at the distance.

\section{Results}

The sympathomimetic drugs caused an increase in diameter in the right 'fixed' dilated pupil of 21 to

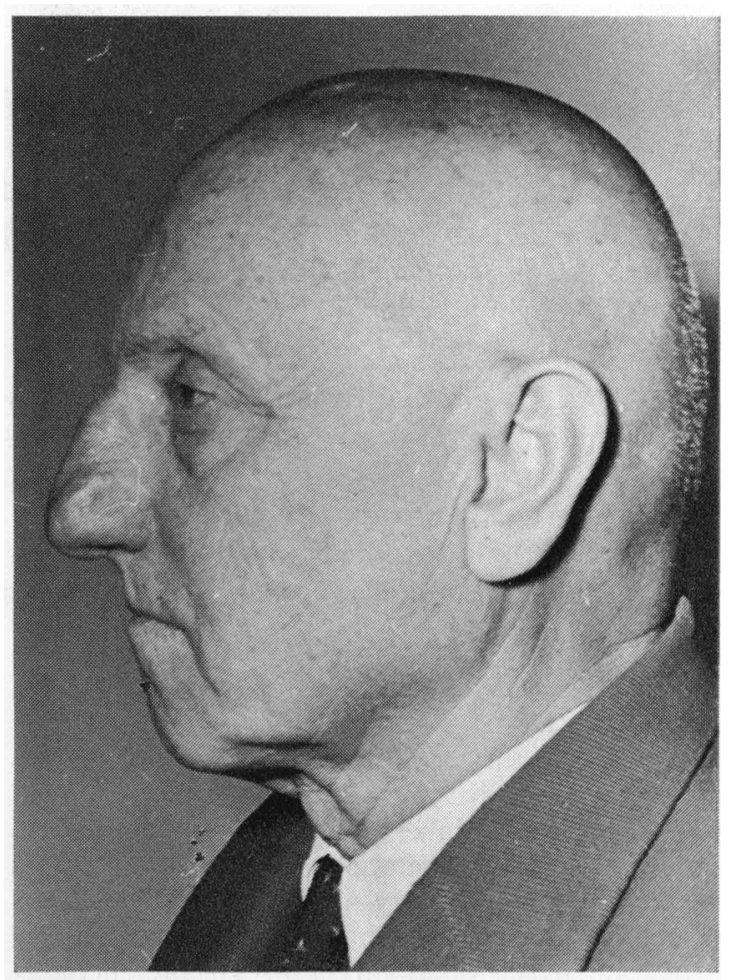

Fig. $1 a, b$ Frontal and lateral facial photographs of patient. Note the appearance of blepharophimosis, heterochromia iridis, anisocoria, and a broad prominent nose. The furrow on the nose is just seen

$28 \%$ and in the left pupil of 100 to $133 \%$. There was a concomitant increase in the palpebral fissure. Pilocarpine $(0.02 \%)$ constricted the normal left pupil to a diameter of $2.5 \mathrm{~mm}$, phospholine iodidide $(0.06 \%)$ to a diameter of $2 \mathrm{~mm}$. The right pupil did not react to either drug, even at concentrations of $2 \%$ and $0 \cdot 12 \%$ respectively. Both pupils reacted to guanethidine; the right one contracted to a diameter of $6 \mathrm{~mm}$ and the left one to $2.5 \mathrm{~mm}$. These results are summarised in Table 2.

\section{Discussion}

The concurrence of heterochromia and anisocoria is a common sign in Horner syndrome which appears in infancy (Waardenburg et al., 1961). In the present case the sympathetic innervation of the abnormal pupil is intact. The dilator muscle responded to the direct adrenergic agonist, phenylephrine, as well as to hydroxyamphetamine, which acts through release of catecholamines from sympathetic terminals. Moreover, norepinephrine was spontaneously released from the ocular sympathetic nerves in both 
eyes; guanethidine caused miosis and cocaine dilated both pupils. Thus the diminished pigmentation of the abnormal iris and fundus is not likely to be due to a latent Horner syndrome. The reaction of the pupil to adrenergic and sympatholytic agents also

dB

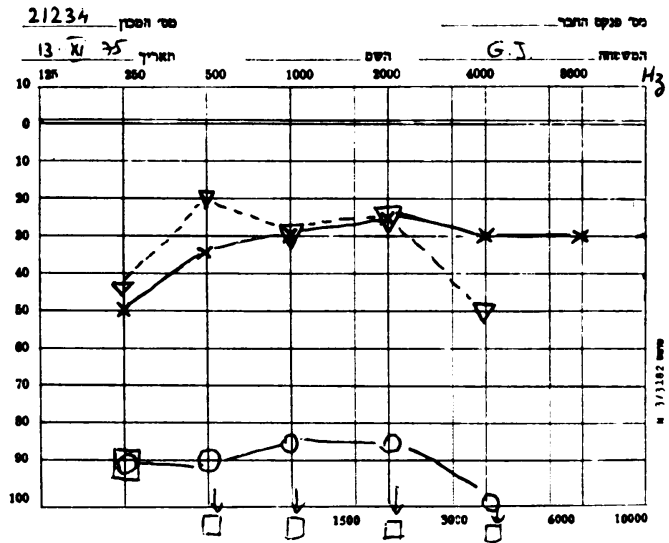

Fig. 2 Audiometry of patient. There is complete right ear deafness, with mild hearing loss on the left

$\mathbf{X}$-Left ear, air conduction; $\nabla$-left ear, bone conduction; $\square$-right ear, air conduction; O-right ear, bone conduction

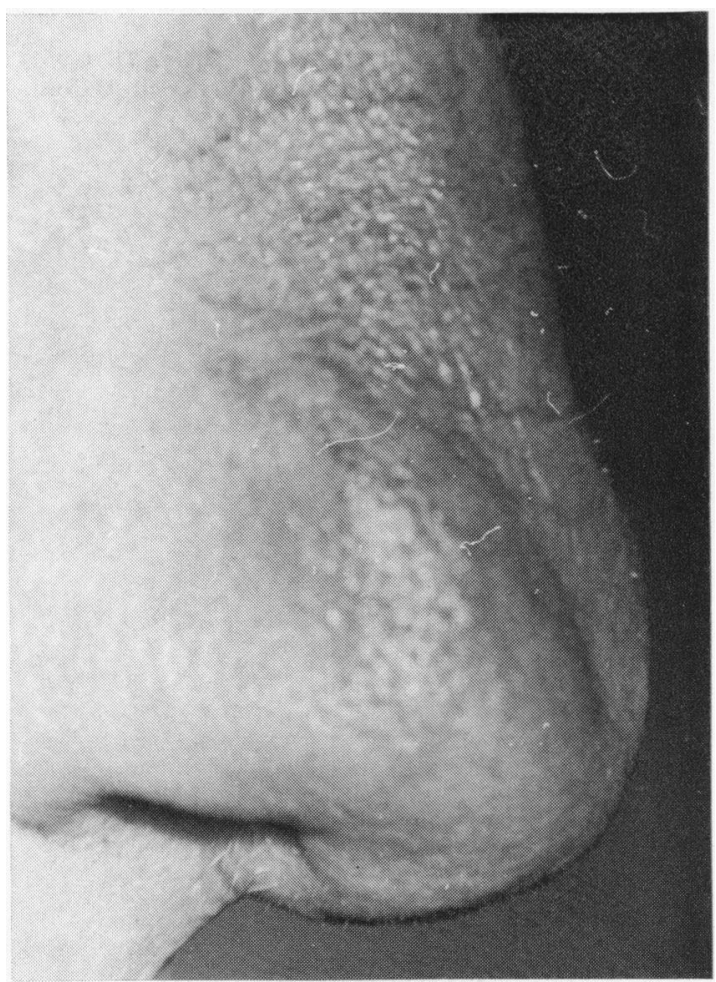

Fig. 3 Oblique furrow on right side of nose is seen eliminates mechanical factors as an explanation for its immobility in response to light.

In the absence of local ocular causes fixed dilated pupils are usually caused by interruption of the parasympathetic innervation to the iris. Acquired lesions of the parasympathetic pathway to the eye either have no effect on or increase the response to cholinergic agonists. However, in our patient the ab-

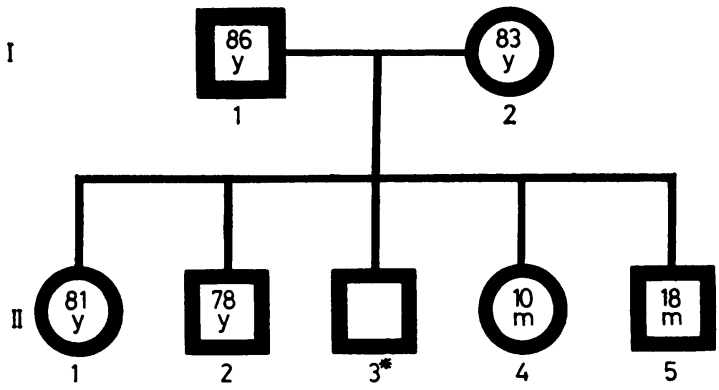

Fig. 4 Pedigree of Family $P$. The propositus is the only survivor of 5 siblings; the others have died of unknown causes at the ages mentioned. According to the subject the father had a white forelock and heterochromia iridis. Brother $\mathrm{II}_{2}$ was severely affected. He was deafmute and had heterochromia iridis, a white forelock, and a cleft lip. Siblings $\mathrm{II}_{2}, \mathrm{II}_{4}$, and $\mathrm{II}_{5}$ as well as the father are said to have had 'little eyes', resembling those of the propositus, possibly implying dystopia of the medial canthi. The inheritance is most likely due to autosomal recessive inheritance with variable penetrance

Table 1 Ophthalmological status

\begin{tabular}{|c|c|c|}
\hline & Right eye & Left eye \\
\hline Conjunctivae & Normal & Normal \\
\hline Cornea & Normal & Normal \\
\hline Anterior chamber & Normal & Normal \\
\hline $\begin{array}{l}\text { Intraocular pressure } \\
\quad(\mathrm{mmHg})\end{array}$ & $21-22$ & $19-21$ \\
\hline Pupil & $\begin{array}{l}\text { Semidilated }(7 \mathrm{~mm}) \\
\text { fixed to light and } \\
\text { attempted convergence }\end{array}$ & $\begin{array}{l}3 \mathrm{~mm}(200 \mathrm{~lx}) \\
\text { Normal light and } \\
\text { near responses }\end{array}$ \\
\hline Iris & $\begin{array}{l}\text { Blue; stromal atrophy; } \\
\text { intact pigment layer }\end{array}$ & Brown, normal \\
\hline Lens & $\begin{array}{l}\text { Posterior capsular } \\
\text { cataract }\end{array}$ & Normal \\
\hline Fundus & Myopic disc & Myopic disc \\
\hline $\begin{array}{l}\text { Visus } \\
\text { Distance }\end{array}$ & $\begin{array}{l}-3 \cdot 50 \mathrm{DS} \\
-2 \cdot 00 \text { cyl. axis } \\
180^{\circ} \\
6 / 12\end{array}$ & $\begin{array}{l}-2.00 \mathrm{DS} \\
+2 \cdot 00 \mathrm{cyl} . \text { axis } \\
180^{\circ} \\
6 / 9\end{array}$ \\
\hline Reading & $\begin{array}{l}+3.50 \mathrm{DS} \\
\text { Jaeger } 5\end{array}$ & $\begin{array}{l}+3.5 \mathrm{DS} \\
\text { Jaeger } 1\end{array}$ \\
\hline
\end{tabular}


Table 2 Pupillary diameter ( $\mathrm{mm}$ ) after various drugs

\begin{tabular}{llc}
\hline & Right pupil & Left pupil \\
\hline Resting diameter (200 Lx) & 7 & 3 \\
Phenylephrine 5\% & 9 & 7 \\
Cocaine 4\% & 8.5 & 6 \\
Hydroxyamphetamine 1\% & 8.5 & 7 \\
Pilocarpine 0.08\% & 7 & 3 \\
$\quad 0.02 \%$ & 7 & 2.5 \\
$0.03-2 \%$ & 7 & $<2$ \\
Phospholine iodide 0.06-0.12\% & 7 & $<2$ \\
Guanethidine 1\% & 6 & 2.5 \\
\hline
\end{tabular}

normal pupil did not respond even to high concentrations of cholinomimetic drugs (Table 2). Neither did he have accommodation. Thus we conclude that the sphincter pupillae does not exist (or does not contain cholinergic receptors, an unlikely alternative).

Both pupillary muscles develop from the optic cup and do not require automatic induction (Kronfeld, 1969); rather, the autonomic nerves are attracted to the eye by the developing optic cup (Arey, 1966). Thus one could postulate agenesis of the ciliary ganglion in this patient. Goldberg's (1963) patient with WS associated with congenital aganglionic colon suggests that parasympathetic ganglion agenesis may occasionally also occur at other sites.
We are grateful to the patient for permitting us to make repeated examinations, and to K. J. Shoham for his helpful ophthalmological advice.

\section{References}

Arey, L. B. (1966). Developmental Anatomy, 7th edn., pp. 500-520. Saunders: Philadelphia.

DiGeorge, A. M., Olmsted, R. W., Harley, R. D. (1960). Waardenburg's syndrome. Journal of Pediatrics, 57, 649669.

Fisch, L. (1959). Deafness as part of a hereditary syndrome. Journal of Laryngology and Otology, 73, 355-382.

Gambill, H. D., Ogle, K. N., Kearns, T. P. (1967). Mydriatic effects of four drugs determined with pupilograph. Archives of Ophthalmology, 77, 740-746.

Goldberg, M. F. (1966). Waardenburg's syndrome with fundus and other anomalies. Archives of Ophthalmology, 76, 797-810.

Korczyn, A. D., Laor, N., Nemet, P. (1976). Sympathetic pupillary tone in old age. Archives of Ophthalmology, 94, 1905-1906.

Kronfeld, P. D. (1969). The gross anatomy and embryology of the eye. In The Eye, Vol. 1, 2nd edn., pp. 1-66. Edited by $\mathrm{H}$. Davson. Academic Press: New York.

Laor, N., Korczyn, A. D., Nemet, P. (1977). Sympathetic pupillary activity in infants. Pediatrics, 59, 195-198.

Viswanathan, B. (1973). Waardenburg's syndrome. Practitioner, 211, 785-789.

Waardenburg, P. J. (1951). A new syndrome combining developmental anomalies of the eyelids, eyebrows and nose root with pigmentary defects of the iris and head, hair and with congenital deafness. American Journal of Human Genetics, 3, 195-253.

Waardenburg, P. J., Franceschetti, A., Klein, D. (1961). Genetics and Ophthalmology, Vol. 1. Blackwell: Oxford. 